\title{
Effects of resistance training with blood flow restriction on the body composition of postmenopausal women
}

\begin{abstract}
Objective: To evaluate the effect of low load resistance training with blood flow restriction (LLRT+BFR) on the body composition of postmenopausal women and to compare the results with the effects obtained from high load resistance training (HLRT).

Methods: This is a randomized, open label, controlled trial with two parallel arms. Eighteen postmenopausal women $(62,28 \pm 5,07$ years $)$, physically active and functionally independent, were randomly allocated into two groups: LLRT+BFR ( $\mathrm{n}=$ 9) and HLRT $(n=9)$. Body mass index (BMI), waist-hip ratio (WHR), appendicular muscle mass $(\mathrm{AMM})$ and body fat percentage $(\mathrm{BF} \%)$ were tested before, during and after 16 weeks of resistance training. The LLRT+BFR group performed four sets of 15 repetitions with $50 \%$ of the arterial occlusion pressure reduced to $50 \mathrm{mmHg}$ in intervals between series with $30 \%$ of 1RM.The HLRT group performed three series of 10 repetitions with $70 \%$ of $1 \mathrm{RM}$. Both groups performed the free squat exercise with bar twice a week. ANOVA of repeated measures with Bonferroni post hoc were used.
\end{abstract}

Results: After 16 weeks, no significant differences $(p>0,05)$ occurred in the body composition neither intra and nor between groups.

Conclusion: Low load resistance training with blood flow restriction and high load is apparently ineffective in provide changes in body composition.

Keywords:elderly, hypertrophy, ischemia, lean mass, fat mass, sarcopenia, anthropometry
Volume 3 Issue 3 - 2018

\author{
Milla Dayane Leandro da Silva,' Piettra \\ Moura Galvão Pereira, ${ }^{2}$ Amandio Aristides \\ Rihan Geraldes,' Rafael Peron Gomes \\ Fonseca de Farias, ${ }^{3}$ Jakeline Moura dos \\ Santos,' Maria do Socorro Cirilo-Sousa ${ }^{4}$ \\ 'Department of physical education, Federal University of \\ Alagoas, Brazil \\ ${ }^{2}$ Department of physical education, CESMAC University Center, \\ Brazil \\ ${ }^{3}$ Department of physical education, Faculty Estacio of Alagoas, \\ Brazil \\ ${ }^{4}$ Department of physical education, Federal University of \\ Paraíba, Brazil
}

Correspondence: Piettra Moura Galvão Pereira, Doctor, Department of physical education, Federal University of Alagoas, Brazil, Rua Anahy, 259, Pinheiro, Maceió-AL, CEP: 57017-660, Tel +558299666-91 16, Email piettra_galvao@hotmail.com

Received: March 10, 2018 | Published: May 15, 2018

\section{Introduction}

With the aging process, there is a progressive change in the proportion between body components and stature in both sexes ${ }^{1}$ however, women show greater impact on changes in body composition related to aging due to the physiological exhaustion of the ovarian function (menopause) and thus, estrogen declines, ${ }^{2,3}$ amplifying the negative effects of aging on body components such as increase and redistribution of body fat and decrease of muscle and bone mass. ${ }^{4,5}$

Disproportionate changes in body components influence the occurrence of diseases such as obesity, sarcopenia, sarcopenic obesity, osteopenia and osteoporosis, negatively influencing health, functional independence and quality of life. Thus, it is necessary to identify effective strategies for the maintenance of body components within normality parameters; however, without providing reductions in the muscle component in order to maintain levels of strength and physical functionality. ${ }^{6}$

In this perspective, available guidelines recommend that highload resistance training $\left(\mathrm{HL}_{\mathrm{RT}}\right)$ should be used as an interesting and valid strategy to provide changes in body composition of middle-aged and older individuals to reduce body fat percentage (BF\%), increase muscle mass and bone mineral density. ${ }^{7,8}$ Exercise programs should be composed of one to three series consisting of 8-12 repetitions with one to three minutes intervals/ recovery, using intensities between 60 and $80 \%$ of the maximum dynamic force, two to three times a week.
However, despite the possible benefits, especially for more fragile or female elderly, ${ }^{9} \mathrm{HL}_{\mathrm{RT}}$ may not be well tolerated, negatively influencing the adherence of practitioners to the training program. ${ }^{10}$ Thus, activities or resources capable of providing the same benefits of $\mathrm{HL}_{\mathrm{RT}}$ using low training loads / intensities are not only able to minimize the risks or worsening of injuries, but also may favor greater adherence of subjects to this training program. ${ }^{11}$

Studies have shown that low-load resistance training performed with blood flow restriction $\left(\mathrm{LL}_{\mathrm{RT}}+\mathrm{BFR}\right)$ is able to produce similar effects and even superior to those obtained through $\mathrm{HL}_{\mathrm{RT}}$ on hypertrophy ${ }^{12}$ using training loads between 20 and $50 \%$ of the repetition maximal value (1RM). ${ }^{13-15}$ To the best of our knowledge, no study was found in literature using $\mathrm{LL}_{\mathrm{RT}}+\mathrm{BFR}$ in an intervention program to verify changes in body composition in postmenopausal women.

Thus, the present study aimed to evaluate the effect of $\mathrm{LL}_{\mathrm{RT}}+\mathrm{BFR}$ on the body composition of postmenopausal women and to compare the results with the effects obtained from $\mathrm{HL}_{\mathrm{RT}}$.

\section{Methods}

A total of 18 women (age [mean \pm SD]: $62.28 \pm 5.07$ years) were selected to participate in the study according to the following inclusion criteria: physically active - at least seven thousand and five hundred steps daily; ${ }^{16}$ functionally independent; central systolic blood pressure, pulse wave velocity ${ }^{17}$ and normal brachial ankle index, ${ }^{18}$ 
and had not participated in resistance training for at least six months prior to the study. Participants who missed three or more consecutive sessions and those who did not obtain minimum of $75 \%$ attendance at the training sessions were excluded from the sample.

The level of physical activity was measured using accelerometers (WISO PW15, China). Functional independence was assessed with the help of an interview using the Multidimensional Functional Assessment Questionnaire. Central blood pressure and pulse wave velocity were measured with aplanation tonometry by the oscillometric method (Mobil-O-Graph PWA System, Stolberg, Germany) and the brachial ankle index was measured with portable vascular Doppler (DV 610B, MedMega, Brazil).

All participants received information about the benefits and possible risks related to participation in the research and signed the informed consent form. The principles of the Helsinki Declaration of the World Medical Association and the guide for use of human subjects of the American College of Sports Medicine were adopted for this study. The study was approved by the Ethics Research Committee of the Federal University of Alagoas (No. 817.007) and by the Brazilian Registry of Clinical Trials (protocol: RBR-4hqbmf).

\section{Intervention}

Participants in $\mathrm{HL}_{\mathrm{RT}}$ and $\mathrm{LL}_{\mathrm{RT}}+\mathrm{BFR}$ underwent three weeks of familiarization, followed by 16 weeks of training with free squatting exercise with bar twice a week, with a 72-hour interval between sessions. Figure 1 shows the scheme of tests and the order for each of the measurements performed during the experimental period. Participants were randomized for secret allocation into groups. The following groups participated in the analyses: $\mathrm{HL}_{\mathrm{RT}}(\mathrm{n}=9)$ and $\mathrm{LL}_{\mathrm{RT}}+\mathrm{BFR}(\mathrm{n}=9)$. The $\mathrm{HL}_{\mathrm{RT}}$ group performed three series of ten repetitions, with a $60-\mathrm{s}$ interval between series and load of $70 \% 1 \mathrm{RM},{ }^{19}$ while the $\mathrm{LL}_{\mathrm{RT}}+\mathrm{BFR}$ group performed four series of 15 repetitions, with a 30 -s interval between series, with load of $30 \% 1 \mathrm{RM}$. The pressure applied to the cuff for the training was $50 \%$ of restrictive pressure (mean \pm SD: right leg $[83.94 \pm 16.12 \mathrm{mmHg}]$, left leg $[85.83 \pm 19.94 \mathrm{mmHg}])$; however, during the recovery intervals between series, cuffs were deflated and maintained at $50 \mathrm{mmHg}$. Cadence of 2-s was adopted for each phase of the movement (digital metronome; Korg, MA-30, Brazil).

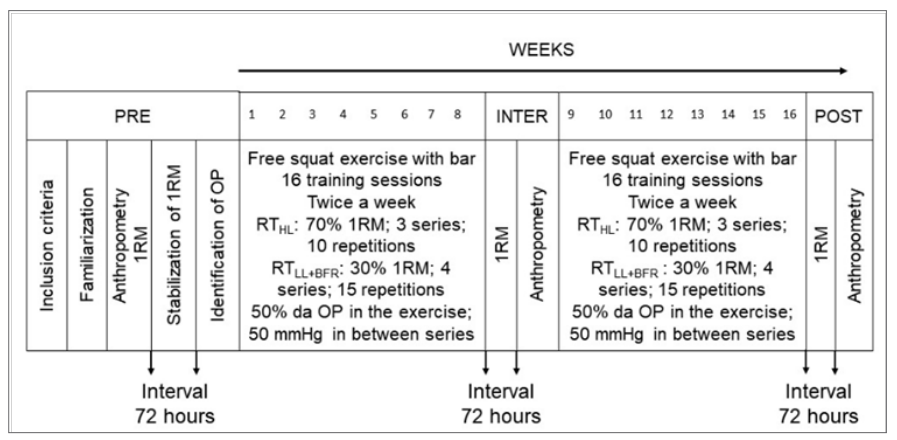

\section{Figure I Experimental timeline}

Before starting the session, warm-up with a five-minute walk was performed, followed by 10 repetitions of squatting, with no additional load. After squatting, all groups ending with 10 minutes of stretching.

To ensure safety, promote adaptation and adherence to training, from the $1^{\text {st }}$ to the $8^{\text {th }}$ week, $\mathrm{HL}_{\mathrm{RT}}$ and $\mathrm{LL}_{\mathrm{RT}}+\mathrm{BFR}$ trained with constant loads. From the $9^{\text {th }}$ to the $16^{\text {th }}$ week, training loads were increased by 1 $\mathrm{kg}$ when the participant was able to perform two additional repetitions in the last series. Participants were evaluated before (PRE), after eight weeks (INTER) and after sixteen weeks (POST).

\section{Determination of the blood flow restriction pressure}

The arterial occlusion point was identified with adapted cuffs (18 $\mathrm{cm}$ in width $\times 90 \mathrm{~cm}$ in length) positioned at the proximal region of the thigh in both limbs with participants in supine position. ${ }^{20}$ Vascular Doppler (DV 610B, MedMega, Brazil) was then positioned over the dorsal pedis artery and the inflated cuffs to the point where the auscultatory pulse of the artery was completely disrupted. The result was recorded in $\mathrm{mmHg}$.

The pressure applied by the cuff to perform restrictive pressure in the $\mathrm{RT}_{\mathrm{LL}}+\mathrm{BFR}$ during training was $50 \%$ of the occlusion pressure (mean \pm SD: right leg $[83.94 \pm 16.12 \mathrm{mmHg}]$; left leg [85.83 \pm 19.94 $\mathrm{mmHg}]$ ), during recovery intervals between series, cuffs were deflated and maintained at $50 \mathrm{mmHg}$.

\section{Anthropometry}

All participants were submitted to anthropometric measures with light clothing, respecting the standardization recommended by Lohman. ${ }^{21}$ Body mass index (BMI) values were obtained by dividing body weigth $(\mathrm{BW})$ by squared stature $(\mathrm{ST})$. BW $(\mathrm{kg})$ was obtained using a digital scale (Plena ${ }^{\circledR}$ MEA-07400, Measurement Specialites, Inc, USA), and $\mathrm{ST}(\mathrm{cm})$ by using a stadiometer (Seca ${ }^{\circledR}$, Baystate Scale \& Systems, USA).

Body perimeters were measured using a flexible inelastic metal Sanny tape (American Medical do Brazil Ltda., São Bernardo do Campo, SP). The waist-hip ratio (WHR) was obtained by divide the waist circumference (WC) by the hip, which was measured at the point of greatest circumference. WC was measured at the midpoint between the last rib and the iliac crest.

The appendicular muscle mass was estimated with the equation of Pereira et al. ${ }^{22}$ using anthropometric measures BW,ST, hip circunference and forearm perimeter (PANT), at the point of greatest forearm circumference. $\mathrm{BF} \%$ was estimated using the equation of Deurenberg $^{23}$ using BMI, age and sex, and the value of zero was attributed to female sex.

All measurements were performed by a single trained evaluator. Reproducibility was verified with the intraclass correlation coefficient. Values for body perimeters from 0.83 to 0.98 were observed.

\section{Statistical Analyses}

Data normality and homogeneity was evaluated by the ShapiroWilk and Levene test. ANOVA of repeated measures for the factors time (PRE, INTER and POST) and group $\left(\mathrm{HL}_{\mathrm{RT}}, \mathrm{LL}_{\mathrm{RT}}+\mathrm{BFR}\right)$ was used. To guarantee the validity of results, a reproducibility analysis $(n=10)$ was performed by intraclass correlation coefficient. The sample size was previously estimated (power of $0.90, \alpha$ of 0.05 , effect size of 0.26 and correlation of 0.75 ) with data from a pilot study. The $\mathrm{G}^{*}$ Power statistical software version 3.0.10 and SPSS 20.0 were used.

\section{Results}

Descriptive characteristics and inclusion criteria of the sample can be observed in Table 1. There was no significant difference between groups at the PRE-intervention time $(\mathrm{p}>0.05)$ for all variables. 
Inter and intra group comparisons can be observed in Figure 2. When groups were compared, no significant difference was observed between moments for variables BMI, WHR, AMM and BF\% ( $p>0.05)$.

Table I Characterization of participants and inclusion criteria and comparison between groups

\begin{tabular}{|c|c|c|}
\hline & $\begin{array}{l}\text { High Load } \\
(n=9)\end{array}$ & $\begin{array}{l}\text { Low load and } \\
\text { blood flow } \\
\text { restriction } \\
(n=9)\end{array}$ \\
\hline Age (Years) & $62.67 \pm 5.17$ & $61.78 \pm 4.99$ \\
\hline Stature $(\mathrm{cm})$ & $153.72 \pm 8.89$ & $153.94 \pm 6.89$ \\
\hline Body mass $(\mathrm{kg})$ & $63.31 \pm 8.72$ & $66.27 \pm 6.05$ \\
\hline Body mass index $\left(\mathrm{kg} \mathrm{m}^{-2}\right)$ & $27.39 \pm 2.43$ & $27.62 \pm 2.34$ \\
\hline $\begin{array}{l}\text { Appendicular muscle mass } \\
(\mathrm{kg})\end{array}$ & $15.66 \pm 2.58$ & $15.97 \pm 1.66$ \\
\hline Body fat (\%) & $41.76 \pm 3.53$ & $41.89 \pm 2.69$ \\
\hline waist-hip ratio $(\mathrm{cm})$ & $0.85 \pm 0.06$ & $0.86 \pm 0.07$ \\
\hline $\begin{array}{l}\text { Right brachial ankle index } \\
(\mathrm{mmHg})\end{array}$ & $1.12 \pm 0.08$ & $1.10 \pm 0.08$ \\
\hline $\begin{array}{l}\text { Left brachial ankle index } \\
(\mathrm{mmHg})\end{array}$ & $1.09 \pm 0.10$ & $1.12 \pm 0.11$ \\
\hline Pulse wave velocity $\left(\mathrm{ms}^{-1}\right)$ & $8.72 \pm 0.96$ & $8.67 \pm 0.87$ \\
\hline $\begin{array}{l}\text { Central blood pressure } \\
(\mathrm{mmHg})\end{array}$ & || $3.44 \pm|| .6 \mid$ & $115.22 \pm 10.44$ \\
\hline Number of steps & $8246.48 \pm 2042.48$ & $8687,77 \pm 2748,74$ \\
\hline
\end{tabular}

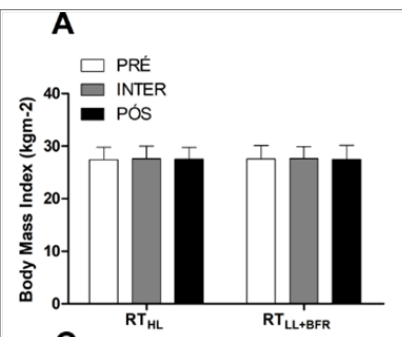

$$
\text { C }
$$
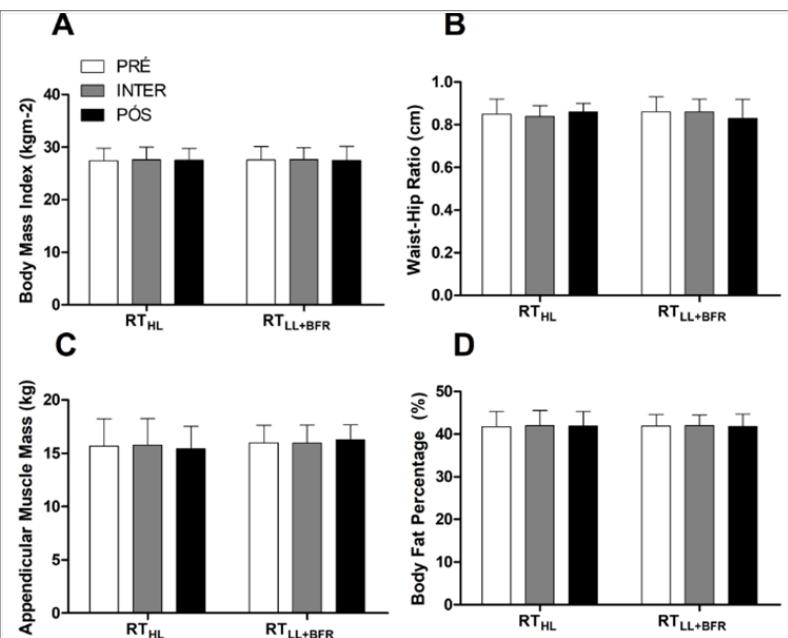

D

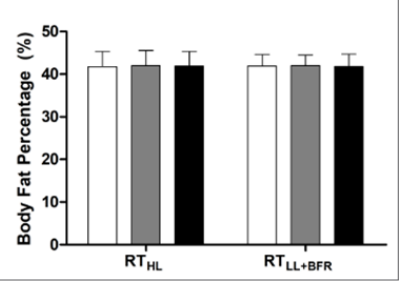

Figure 2 A, Body mass index; B, Waist-hip ratio; C,Appendicular muscle mass; $D$, Body fat in groups resistance training with high load $\left(R T_{H L}\right)$ and low load with blood flow restriction ( $\mathrm{RT}_{\mathrm{LL}}+\mathrm{BFR}$ ) at moments.

\section{Discussion}

The present study verified and compared the effects of $\mathrm{HL}_{\mathrm{RT}}$ and $\mathrm{LL}_{\mathrm{RT}}+\mathrm{BFR}$ on body composition in postmenopausal women submitted to 16 weeks of training with free squatting exercise. To our knowledge, the present study was the first to evaluate the effects of both types of training on body composition in postmenopausal women. No significant inter and intra-group differences in BMI, WHR, AMM and BF\% were observed after intervention.

Only the study by Araújo et al. ${ }^{1}$ was observed in our literature searches evaluating a set of body composition variables after intervention with aerobic aquatic exercises with and without blood flow restriction. The authors ${ }^{1}$ submitted 29 middle-aged women ( $54 \pm 4.1$ years) to training, three days a week, for eight weeks. The groups (with and without blood flow restriction) performed four series, the first one with 30 and the other with 15 repetitions, the intensity was measured with an effort perception scale from 6 to 20, on which participants should report values from 9 to 11 . Similarly to the present study, the authors did not observe significant differences in body mass, skeletal muscle mass, fat body mass, BMI, BF\% and WHR after intervention ( $\mathrm{p}>0.05)$.

Although both studies presented similar results, comparisons made with the study by Araújo et al. ${ }^{1}$ would not be adequate, since the intervention was performed through aerobic training in the aquatic environment, unlike the present study, conducted with strength training and in terrestrial environment. In addition to the aerobic or anaerobic energy demand involved in both training protocols, when exercises are performed in the water, thrust pushes the blood to the upper limbs so that blood restriction naturally occurs.

Specifically on changes in skeletal muscle mass, some studies have observed significant changes in the cross-sectional area of the quadriceps as measured by magnetic resonance imaging in middleaged and older adults of both sexes ${ }^{24-26}$ after $\mathrm{LL}_{\mathrm{RT}}+\mathrm{BFR}$ programs for lower limbs for at least eight weeks. In the present study, the crosssectional area of the quadriceps was not measured; however, no changes were observed in AMM after intervention programs ( $p>0.05)$.

Unlike results observed in the present study, Nunes ${ }^{27}$ observed significant changes in $\mathrm{BF} \%$ of postmenopausal women after 16 weeks of intervention when using HLRT (70\% of 1RM), with high and low training volumes, however, no significant difference was observed in WC and WHR in the group submitted to low training volumes (three times a week), similarly to the present study. Chen et al. ${ }^{8}$ investigated the effects of $\mathrm{HL}_{\mathrm{RT}}$ after eight weeks of intervention and, despite observing significant differences in the control group, similarly to the present study, significant differences in $\mathrm{AMM}$ and $\mathrm{BF} \%$ were not observed at the end of intervention in the $\mathrm{HL}_{\mathrm{RT}}$ group.

Thus, such adaptations in body composition seem mainly related to the time of intervention and the high training volume. In addition, it is necessary to point out that such studies used more sensitive methods to detect differences in body composition such as computed tomography, plestimography and dual energy absorptiometry.

\section{Acknowledgements}

The authors thank the participants who submitted to the study. We also thank the Hospital of the Heart of Alagoas that provided the Applanation Tonometry examinations and the University Hospital of the Federal University of Alagoas for the Computed Tomography examinations.

\section{Conflict of interest}

The authors declare no conflict of interest.

\section{References}

1. Araújo JP, Rodrigues Neto G, et al. Does Water Aerobics with Blood Flow Restriction Change the Body Composition?. J Exerc Physiol Online. 2015;18:25-31.

2. Maltais ML, Desroches J, Dionne IJ. Changes in muscle mass and strength after menopause. J Musculoskelet Neuronal Interact. 2009;9(4):186-97. 
3. Toth MJ, Tchernof A, Sites CK, et al. Menopause-related changes in body fat distribution. Ann N Y Acad Sci. 2000;904:502-6.

4. Gallagher D, Ruts E, Visser M, et al. Weight stability masks sarcopenia in elderly men and women Weight stability masks sarcopenia in elderly men and women. Am J Physiol Endocrinol Metab. 2000;279:E366-75.

5. Newman AB, Lee JS, Visser M,et al. Weight change and the conservation of lean mass in old age: the Health, Aging and Body Composition Study. Am J Clin Nutr. 2005;82:872-878.

6. Campbell WW, Haub MD, Wolfe RR, et al. Resistance training preserves fat-free mass without impacting changes in protein metabolism after weight loss in older women. Obesity (Silver Spring). 2009;17:1332-9.

7. Avila JJ, Gutierres JA, Sheehy ME, et al. Effect of moderate intensity resistance training during weight loss on body composition and physical performance in overweight older adults. Eur J Appl Physiol. 2010;109:517-25.

8. Chen HT, Chung YC, Chen YJ, et al. Effects of Different Types of Exercise on Body Composition, Muscle Strength, and IGF-1 in the Elderly with Sarcopenic Obesity. J Am Geriatr Soc. 2017;65:827-32.

9. Izquierdo M, Cadore EL. Muscle power training in the institutionalized frail: a new approach to counteracting functional declines and very late-life disability. Curr Med Res Opin. 2014;908175:1-6.

10. Boyette LW, Lloyd A, Boyette JE, et al. Personal characteristics that influence exercise behavior of older adults. J Rehabil Res Dev. 2002;39:95-103.

11. Karabulut M, Abe T, Sato Y, et al. Overview of neuromuscular adaptations of skeletal muscle to KAATSU Training. Int $J$ KAATSU Train Res. 2007;3:1-9.

12. Pearson SJ, Hussain SR. A Review on the Mechanisms of Blood-Flow Restriction Resistance Training-Induced Muscle Hypertrophy. Sport Med [Internet]. 2014;45:187-200.

13. Loenneke JP, Wilson GJ, Wilson JM. A mechanistic approach to blood flow occlusion. Int J Sports Med. 2010;31:1-4.

14. Yasuda T, Ogasawara R, Sakamaki M, et al. Combined effects of low-intensity blood flow restriction training and high-intensity resistance training on muscle strength and size. Eur J Appl Physiol. 2011;111:2525-33.

15. Sumide T, Sakuraba K, Sawaki K, et al. Effect of resistance exercise training combined with relatively low vascular occlusion. J Sci Med Sport. 2009;12(1):107-12.
16. Tudor LC, Craig CL, Thyfault JP, et al. A step-defined sedentary lifestyle index: <5000 steps/day. Appl Physiol Nutr Metab. 2013;38:100-14.

17. Weiss W, Gohlisch C, Harsch GC, et al. Oscillometric estimation of central blood pressure: validation of the Mobil-O-Graph in comparison with the SphygmoCor device. Blood Press Monit. 2012;17:128-31.

18. Resnick HE, Lindsay RS, McDermott MM, et al. Relationship of high and low ankle brachial index to all-cause and cardiovascular disease mortality: the Strong Heart Study. Circulation. 2004;109:733-9.

19. Chodzko ZWJ, Proctor DN, Fiatarone SMA, et al. ACSM. Exercise and physical activity for older adults. Med Sci Sports Exerc. 2009;41:1510-30.

20. Laurentino G, Ugrinowitsch C, Aihara Y, et al. Effects of strength training and vascular occlusion. Int J Sports Med. 2008;29:664-7.

21. Lohman T. Advances in body composition assessments. Humn Kinet. Champaign IL; 1992.

22. Pereira P, da Silva G, Santos Jr G, et al. Development and validation of anthropometric equations to estimate appendicular muscle mass in elderly women. Nutr J. 2013;12:1-11.

23. Deurenberg P, Weststrate AJ, Seidell CJ. Body mass index as a measure of body fatness: age-and sex- specific prediction formulas. $\mathrm{Br} \mathrm{J} \mathrm{Nutr}$. 1991;65:105-14.

24. Vechin FC, Libardi CA, Conceição MS, et al. Comparisons Between Low-Intensity Resistance Training With Blood Flow Restriction and High-Intensity Resistance Training on Quadriceps Muscle Mass and Strength in Elderly. J Strength Cond Res. 2015;29:1071-6.

25. Yasuda T, Fukumura K, Fukuda T, et al. Muscle size and arterial stiffness after blood flow-restricted low-intensity resistance training in older adults. Scand J Med Sci Sport. 2014;24:799-806.

26. Yasuda T, Fukumura K, Uchida Y, et al. Effects of low-load, elastic band resistance training combined with blood flow restriction on muscle size and arterial stiffness in older adults. Journals Gerontol - Ser A Biol Sci Med Sci. 2014;70:950-8.

27. Nunes PRP, Barcelos LC, Oliveira AA, et al. Effect of resistance training on muscular strength and indicators of abdominal adiposity, metabolic risk, and inflaAMMtion in postmenopausal women: controlled and randomized clinical trial of efficacy of training volume. Age (Omaha). AGE 2016;38(2):40. 